Artigo

\title{
Reconhecimento, identidade(s) e conflito social Debates a partir da teoria política e social
}

\author{
Recognition, identity and social conflict
}

Debates in the perspective of political and social theory

\section{Reconocimiento, identidad y conflicto social}

Debates a partir de la teoría política y social

\author{
Daquel Kritsch ${ }^{1}$ \\ Raissa Wihby Ventura ${ }^{2}$
}

\begin{abstract}
Resumo: Os debates identitários têm ocupado parte significativa das reflexões das ciências sociais nas últimas décadas, impulsionados em boa medida pelas formulações de autoras/es que se debruçaram sobre o tema do reconhecimento. As posições e as disputas são muitas e têm se avolumado sobremaneira, mas talvez seja possível ordenálas em torno de uma discussão comum, como propõe Rahel Jaeggi. Para tanto, optamos por reconstruir e interpretar as noções de reconhecimento e identidade propostas por Charles Taylor, Axel Honneth e Judith Butler, procurando mostrar que há uma conexão subjacente a essas perspectivas, raramente lidas como parte de uma mesma tradição, a saber, a herança hegeliana. Por fim, discutimos as diferenças substantivas entre uma noção positiva e outra negativa do reconhecimento e das identidades e apontamos as potencialidades de uma agenda de pesquisa em ciências sociais e humanas que adote algumas das premissas fundamentais do reconhecimento negativo.
\end{abstract}

Palavras-chave: Reconhecimento. Identidades. Conflito social. Teoria política e social.

Abstract: Identity debates have been a significant part of the reflections of the social sciences in the last decades, stimulated to a large extent by the authors' formulations that dealt with the subject of recognition. The views and disputes on this subject are many, and they have greatly increased; but it may be possible to organize them around a common discussion, as proposed by Rahel Jaeggi. We chose to present the notions of recognition and identity proposed by Charles Taylor, Axel Honneth and Judith Butler, trying to show that there is a connection underlying these perspectives, which are rarely read as part of the same tradition, namely, the Hegelian inheritance. Finally, we discuss the substantive differences between a positive and a negative notion of recognition and identities, and we point out the potentialities of a research agenda in social and human sciences that adopts some of the fundamental premises of negative recognition.

Keywords: Recognition. Identities. Social conflict. Political and social theory.

\footnotetext{
${ }^{1}$ Universidade Estadual de Londrina (UEL, Londrina, PR, Brasil).

${ }^{2}$ Universidade de São Paulo (USP, São Paulo, SP, Brasil).

author.biographic_data
}

Civitas, Porto Alegre, v. 19, n. 2, p. 441-463, maio-ago. 2019

Este artigo está licenciado sob forma de uma licença Creative Commons Atribuição 4.0 Internacional, que permite uso irrestrito, distribuição e reprodução em qualquer meio, desde que a publicação original seja corretamente citada. https://creativecommons.org/licenses/by/4.0/deed.pt BR 
Resumen: Los debates identitarios ocuparan parte significativa de las reflexiones de las ciencias sociales en las últimas décadas, impulsados en buena parte por las formulaciones de autoras que se centraron en el tema del reconocimiento. Las posiciones y las disputas son muchas y se han agravado sobremanera; pero tal vez sea posible ordenarlas en torno a una discusión común, como propone Rahel Jaeggi. Para tanto, optamos por reconstruir e interpretar las nociones de reconocimiento e identidad propuestas por Charles Taylor, Axel Honneth y Judith Butler, buscando mostrar que hay una conexión subyacente a esas perspectivas, raramente leídas como parte de una misma tradición, a saber, la herencia hegeliana. Por último, discutimos las diferencias sustantivas entre una noción positiva y otra negativa del reconocimiento y de las identidades y señalamos las potencialidades de una agenda de investigación en ciencias sociales y humanas que adopte algunas de las premisas fundamentales del reconocimiento negativo.

Palabras-clave: Reconocimiento. Identidades. Conflicto social. Teoría política y social.

\section{Introdução ${ }^{1}$}

As questões relacionadas ao tema da(s) identidade(s) têm ocupado parte significativa das reflexões das ciências sociais nas últimas décadas. Desde pelo menos os anos 1980, quando as ideias em torno do multiculturalismo e seus dilemas ganharam espaço nas agendas acadêmicas, as teorias políticas e sociais procuram formular conceitos capazes de abarcar noções supostamente antitéticas como igualdade, diferença, tradição, modernidade etc. Para alguns, trata-se de fazer uma opção por um dos termos ou polos (Taylor, 2000; Honneth, 2003); para outros, é preciso forjar chaves analíticas capazes de operar com as dualidades (Fraser, 2001), enquanto para terceiros, ainda, é a própria epistème ocidental que tem de ser desmontada e substituída por noções e conceitos ainda não "colonizados" (Lugones, 2008) ou então ressignificada (Butler, 2004).

Embora a discussão multiculturalista tenha se revelado pouco frutífera, tendo sido praticamente abandonada nos anos 1990, os termos do debate permaneceram e tomaram novas formas. A irredutibilidade das diversidades e das "concepções plurais de bem", pressupostas nas disputas internas às democracias liberais constitucionais e presentes nas práticas sociais de boa parte das sociedades ditas ocidentais, continuaram a desafiar o pensamento social e político. Afinal, o reconhecimento do pluralismo (que seria conceituado de inúmeras maneiras: moral, político, de valores) como um fato incontornável

\footnotetext{
${ }^{1}$ Investigação vinculada ao projeto de pesquisa intitulado Para além da constelação nacional? Disputas em torno da cidadania, do cosmopolitismo e dos direitos humanos na teoria política contemporânea III, financiado pelo CNPq (308475/2017-8) e apoiado pela Universidade Estadual de Londrina.
} 
parecia ter-se tornado lugar comum nas várias ciências humanas, da filosofia à antropologia (Craig, 2004).

Falar em sociedades plurais significa, em um sentido sociológico quase trivial, sustentar que elas incorporam uma variedade de modos de vida, padrões morais e religiosos. Já a discussão filosófica em torno das impossibilidades de continuarmos a aspirar algum tipo de hegemonia sobre o conjunto de considerações éticas existentes ocorria no mesmo momento em que, ganhava espaço o diagnóstico segundo o qual as diferenças culturais, simbólicas e valorativas pareciam ter deslocado a desigualdade socioeconômica como preocupação nuclear. Um deslocamento, importa ressaltar, com implicações tanto para a teoria social e política contemporânea quanto para as dinâmicas sociopolíticas que orientam as ações de pessoas e grupos (Phillips, 2009).

Esta preocupação com a diferença foi acompanhada da constatação de que relações desiguais de poder negavam reconhecimento a grupos minoritários (Coole, 1996); demandas por "reconhecimento das diferenças" passaram assim a dar o tom à luta de grupos mobilizados sob as bandeiras nacionalidade, etnicidade, raça, gênero e sexualidade. Por meio desse movimento, identidades grupais substituiriam paulatinamente os antigos interesses de classe do capitalismo fordista como principal incentivo para a organização e mobilização políticas. Outras formas de subjugação iriam acoplar-se e/ou sobrepor-se à exploração de classe entendida como injustiça fundamental, em um movimento que tornava difícil evitar a ideia de deslocamento [displacement] quando se tem a pretensão de compreender determinados processos sociais em curso, como o deslocamento do material para o cultural, da política de classe para a política de identidade ou ainda da economia da igualdade para a política da reforma constitucional (Phillips, 2009, p. 223).

Tais “deslocamentos" receberam vários nomes por parte dos pensadores da teoria social e política contemporânea, aparecendo ora como "lutas por reconhecimento" (como em C. Taylor, N. Fraser ou A. Honneth), ora como "movimentos por identidade e/ou diferença" ou ainda "política da diferença" (caso de I. Young e W. Connoly.), ora como "movimentos por direitos culturais e pela cidadania multicultural" (como entendem W. Kymlicka e B. Parekh). Todas essas denominações representam, em grande medida, "demandas por presença política" (Phillips, 2009): a reivindicação, para muitos desses grupos excluídos, desfavorecidos e/ou discriminados não é mais apenas eliminar as desigualdades sociais e econômicas, mas sobretudo anular a degradação, o desrespeito e todas as demais formas de opressão de natureza "simbólica", como a viciosidade da violência doméstica ou das agressões raciais, a desvalorização das sexualidades consideradas desviantes e tantas outras formas de opressão 
e dominação. Assim, as categorias fundantes e mobilizadoras dessas lutas não são mais "igual distribuição" ou "igualdade econômica", e sim "dignidade" e "respeito". Reconhecimento torna-se a palavra-chave a ser disputada.

Em meio à diversidade de abordagens dedicadas ao tema do reconhecimento, duas grandes direções podem ser apontadas na teoria social e política recente como merecedoras de destaque e serão objeto de reflexão neste artigo: de um lado, em um eixo que poderíamos denominar como o de uma certa teoria crítica, está uma linhagem inaugurada por Taylor (2000) e refinada por Honneth $(2003)$ e Fraser $(2001 ; 2003)$ ao longo dos anos 1990, que mantém-se nos termos da tradição sociológica que trata a modernidade como um "projeto inacabado" a ser aperfeiçoado por meio da crítica.

De outro lado, há uma miríade de autores/as com filiações diversas que, apesar de toda diversidade, e abraçando o paradigma discursivo de matriz pós-moderna e/ou pós-estruturalista, criticam a essencialização identitária promovida pelos "clássicos" do debate em torno do reconhecimento e propõem uma abordagem antiessencialista, situacional e contingente da(s) identidade(s) (Mohanty, 1984; Mouffe, 1993; Butler, 1998; Young, 2009). Explorar e discutir essas duas matrizes do debate acerca da(s) identidade(s) e do reconhecimento na teoria social e política constitui assim o objetivo central deste artigo.

Para levar a bom termo esse percurso, o artigo foi divido em quatro partes. Optou-se por reconstruir e interpretar a noção de reconhecimento e identidade proposta por Taylor, Honneth e Butler, representantes ilustres, respectivamente, do debate liberal-comunitário, da teoria crítica e do pós-estruturalismo correntes que, pode-se assumir sem grandes ressalvas, constituem hoje as principais influências analíticas dos debates contemporâneos em teoria política e social. A pretensão com esse recorte é a de mostrar que há uma conexão subjacente a essas perspectivas, raramente lidas como parte de uma mesma tradição. Parece ser possível sustentar que o elemento comum a unir perspectivas e autores e autoras tão distintos/as repousa na proposta, comum a todos/as, de um retorno - ainda que propondo interpretações significativamente diferentes - à tradição hegeliana ${ }^{2}$ como matriz de uma perspectiva crítica.

Por fim, na quarta e última seção, procuraremos sustentar tanto a existência de pontos de contato entre essas posições quanto estabelecer

\footnotetext{
${ }^{2}$ A posição de Fraser, apesar de constituir parte fundamental do debate, especialmente para aquele/as que estudam os movimentos sociais e suas militâncias, não será objeto de discussão aqui, pois seus trabalhos - e em especial seu debate com Honneth - são tributários de uma interpretação da teoria crítica que remontaria a Kant, e não a Hegel. Tratar o problema do reconhecimento e das identidades também a partir de uma matriz kantiana exigiria aprofundar uma discussão que não cabe nos limites deste artigo.
} 
as diferenças substantivas entre uma noção positiva e outra negativa do reconhecimento e das identidades (Rahel Jaeggi) para, ao final, apontarmos as potencialidades de uma agenda de pesquisa em ciências sociais que adote algumas das premissas fundamentais do reconhecimento negativo, tal como proposto por Judith Butler.

\section{A politização das lutas sociais por reconhecimento segundo Charles Taylor}

Charles Taylor (2000) argumenta que, na modernidade, a identidade é formada e definida pela existência ou pela inexistência de reconhecimento. A noção de "pessoa", ele procura mostrar, teria sofrido alterações importantes ao longo da história do Ocidente.

Durante muito tempo, explica ele, o lugar do sujeito foi determinado por fatores externos à pessoa, ligados a noções como "status" e "honra" ideias que serviam para fundamentar hierarquias sociais específicas. Assim, antigamente, a "identidade" das pessoas era "regulada" por meio dos papéis sociais que elas desempenhavam. Tais identidades ele chama de "identidades socialmente derivadas", pois se baseavam em categorias sociais exteriores à pessoa, que eram tomadas pelos sujeitos como algo dado e, deste modo, sustentavam e garantiam também o reconhecimento social da pessoa. (Taylor, 2000, p. 248).

Entretanto, o incremento das trocas mercantis e as mudanças sociais introduzidas na era moderna teriam promovido uma mudança no paradigma ético, que teve reflexos importantes sobre a noção de pessoa. Aos poucos, explica o pensador canadense, as pessoas começaram a se conceber como seres com profundidade interna, isto é, como unidades que carregam um valor em $s i$ - como unidades que têm uma medida própria que constitui a marca da originalidade de cada ser humano -, caracterizadas pela dignidade.

Diferentemente da honra, que é sustentada por relações sociais assimétricas, a dignidade se articula como uma categoria comum a todas as pessoas, o que a torna universalizável e potencialmente igualitária. Assim, paulatinamente, o paradigma da dignidade substitui o da honra, provocando uma consequência importante do ponto de vista político, que vai aparecer na esfera pública: a emergência de uma "política do universalismo" (ou uma "política da igualdade", isto é, uma política de exigência da igual dignidade), que visava agora à igualdade de direitos e privilégios, e que iria desembocar mais tarde no princípio democrático da igual cidadania.

Mas esse movimento da honra para a dignidade também criou o seu inverso: uma "política da diferença", que pode ser percebida quando se analisa 
essa mesma transformação do ponto de vista individual, e cujo significado vai aparecer na esfera íntima: com a modernidade, explica Taylor seguindo as pegadas de Hegel, aquilo que mais tarde seria chamado de "identidade da pessoa" começa a ser construído a partir "de dentro" (e não mais de fora, a partir da posição social do sujeito). Nesse processo, que teve como consequência a individualização da identidade, as noções de "bem" e de "mal" deixaram de ser determinadas de fora - por Deus ou outras ordens exteriores - e passaram a ser percebidas como algo enraizado nos próprios sujeitos, agora concebidos como seres naturalmente dotados de sentimentos morais.

Por essa razão, inclusive, é que a busca da autenticidade passa a constituir um ideal: agora, ser autêntico é, em primeiro lugar, ser verdadeiro para comigo, como sugere Rousseau - e não só ser verdadeiro diante de Deus -, o que implica também ser verdadeiro para com a minha originalidade (que é a medida da minha dignidade), que só eu conheço, como ensinou Herder. Essa concepção da identidade como oriunda de dentro de cada ser, explica Taylor, foi justamente o que deu origem à "política da diferença", que visa ao reconhecimento da identidade única, singular de indivíduos ou grupos, raiz das "políticas de reconhecimento" (Taylor, 2000, p. 249-251).

No entanto, diferentemente da "identidade socialmente derivada", a "identidade interiormente derivada", que agora passa a ser "pessoal e original", já não goza mais de um reconhecimento a priori, como tinham aquelas identidades baseadas na honra e na posição social da pessoa. A partir da "virada da subjetividade" provocada pela modernidade, o reconhecimento precisa ser conquistado ativamente pelos sujeitos. E isso só é possível, como já mostrara Hegel, por meio do diálogo e da luta permanente com "outros relevantes". Ou seja, segundo Taylor, Hegel mostra que a autodefinição do self - que supõe a aquisição de linguagens humanas de expressão repletas de significado - só pode ocorrer por meio de "interações comunicativas" e pela da disputa com outros "eus relevantes". Ora, se a formação e manutenção da identidade é dialógica, isto é, implica a negociação com terceiros, ela supõe então o reconhecimento da pessoa ou do grupo. Negar esse reconhecimento, diz Hegel, é uma forma de opressão.

A consequência desse duplo processo, esclarece Taylor, é que vivenciamos uma tensão interminável entre, de um lado, uma "política da diferença", que redefine sempre a não-discriminação como uma exigência, nos levando a fazer distinções com base no tratamento diferencial; e, de outro lado, uma "política da igualdade universal", que luta por formas de não-discriminação que "ignoram" as diferenças entre os cidadãos, fundada na crença de que todos os indivíduos são dignos de respeito igual por partilharem um atributo 
comum a todos os seres humanos, a dignidade, o que gera uma política hostil e/ou cega às diferenças [difference-blind]. Por isso mesmo, o grande desafio hoje, constata o pensador canadense (Taylor, 2000, p. 273), é encontrar um meio-termo entre estes dois princípios que herdamos, o da igualdade e o da diferença.

Argumentos e ideias como essas opunham-se frontalmente ao igualitarismo "cego às diferenças", característico do pensamento liberal bem como de parcelas da esquerda, e exigiam uma séria revisão das posições. Inúmeros/as intelectuais altamente reconhecidos, muitos/as deles/as oriundos do marxismo e dedicados naquele momento aos chamados estudos culturais, cuja ênfase recaía em pesquisas sobre gênero, racismo, sexualidade e outras formas de opressão geradoras de subalternidade, passam a sustentar a necessidade de se pensar a eliminação da desigualdade primordialmente por meio do combate de suas raízes e manifestações culturais e simbólicas.

Com esse movimento, várias questões novas, que incorporam a discussão em torno do par igualdade e diferença, adentram a agenda investigativa: é possível admitir o pluralismo, as minorias e a irredutibilidade das diferenças sem fissurar a coesão interna e os laços de solidariedade do(s) grupo(s) majoritário(s) nesta ou naquela sociedade? Como o reconhecimento e as identidades se relacionam com valores, símbolos e significados culturais afirmados por coletividades particulares? Identidades devem ser pensadas em termos étnicos, grupais ou de autoadscrição? Questões identitárias e de reconhecimento (ou sua carência) podem ser tratadas como injustiças socioculturais e/ou tornarem-se objeto de uma teoria da justiça?

Essas e outras questões de peso marcaram o debate em torno do reconhecimento e das identidades no limiar do milênio, impondo aos pensadores e às pensadoras nas esferas política e social o esforço de buscar respostas para questões que, além de terem ganho sofisticada moldura teórica, revelavam-se cada vez mais prementes no mundo prático, como viriam mostrar os ataques de 11 de setembro nos EUA e seus desdobramentos tanto em termos securitários quanto de migração e circulação de populações no planeta, ou ainda a ascensão de grupos radicais de extrema direita na Europa democrática, os quais em muito pouco tempo passariam a ameaçar o arco-íris multicolor que havia animado as democracias liberais ocidentais no final do século 20 .

\section{Luta por reconhecimento: Axel Honneth e a gramática moral dos conflitos sociais}

O diagnóstico dos deslocamentos levaria também o filósofo alemão Axel Honneth (2007, p. 81) a sustentar que o "reconhecimento" converteu-se 
em uma palavra-chave para compreensão do nosso tempo, tendo sido incorporada à gramática moral dos conflitos sociais. Quer nas discussões sobre o multiculturalismo, quer no autoesclarecimento teórico do(s) feminismo(s), passou a fazer parte do repertório tanto acadêmico quanto militante um ideal que compartilhava a visão normativa de que os indivíduos e/ou grupos deveriam ser aceitos e respeitados em suas diferenças. Em outras palavras, aqueles que se dispuseram a entender os debates acerca da identidade e da diferença, direcionaram suas análises para o desvelamento das bases normativas de reivindicações políticas concretas, que deixaram de refletir desigualdades relacionadas somente à classe social e passaram a incluir demandas por ações afirmativas para mulheres, negros, gays e outras "minorias" discriminadas, oprimidas e/ou excluídas. Pressuposta aqui encontra-se a ideia de que uma concepção compartilhada de justiça estaria essencialmente conectada à preocupação com a maneira pela qual os indivíduos se reconhecem reciprocamente, de modo que eventos experimentados como uma "injustiça" poderiam fornecer os elementos adequados para uma explicação inicial a respeito da conexão interna entre a moralidade e o reconhecimento.

Segundo Honneth (2007), a gramática dos conflitos sociais e sua lógica provêm de experiências morais decorrentes da violação de expectativas normativas de reconhecimento postas em três dimensões centrais: amor, direitos e solidariedade social. O conjunto dessas expectativas forjam a identidade pessoal e permitem a cada qual autocompreender-se como membro autônomo e individualizado, reconhecido nas formas de sociabilidade comum. No momento em que essas expectativas são desapontadas, emerge uma experiência moral que se expressa no desrespeito, o qual pode transformar-se na base motivacional de uma mobilização política se for capaz de expressar um ponto de vista generalizável dentro do horizonte normativo de um grupo. A equação formada por desrespeito, luta por reconhecimento e, quando bemsucedida, a subsequente mudança social constituiria a organização lógica dos movimentos coletivos (Werle e Melo, 2007, p. 28).

Tomando como base os critérios utilizados pelos indivíduos para diferenciar uma ofensa moral de algum tipo de injúria física, não é complicado demonstrar, sugere Honneth (2007, p. 85), que, no primeiro caso, deve haver um elemento de reconhecimento negado ou recusado, enquanto, no segundo, claramente não há lugar para tais referências. Nesse sentido, a injúria física se torna uma injustiça moral se as vítimas são levadas a compreendê-la como uma ação que intencionalmente desprezou e/ou negou um aspecto central do bemestar pessoal delas - das vítimas. É evidente que não constitui injúria moral 
somente a inflição da dor física, mas especificamente a consciência adicional de não ter o seu entendimento reconhecido e aceito.

A tortura e o estupro são bons exemplos de tipos básicos de humilhação física. Isso porque privam os seres humanos da manifestação corporal de sua autonomia em relação a si mesmos, e, portanto, de uma parte de sua confiança elementar em seu mundo. A relação de reconhecimento positivo que corresponde a essa forma de desrespeito, e que leva o indivíduo a construir a autoconfiança corporal, é o cuidado emocional - aquilo que Hegel, filósofo romântico, tentou capturar na ideia de "amor".

Como as necessidades físicas e afetivas só podem ser "validadas", de alguma maneira, por meio do fato de se estar satisfeito ou de se sentir respondido diretamente, o reconhecimento, aqui, deve ter o caráter de aceitação e encorajamento efetivo. Desse modo, a relação de reconhecimento está ligada à existência física dos "Outros concretos", que retribuem seus sentimentos de estima especial. A atitude positiva, surgida do reconhecimento efetivo, que emerge em relação a si próprio é a confiança em si mesmo.

Tal atitude positiva faz referência à camada fundamental de autoconfiança emocional e corporal na expressão das necessidades e sentimentos do indivíduo, que forma as condições para o desenvolvimento de todos os outros aspectos do autorrespeito - para Honneth, esse reconhecimento recíproco só é válido para as ligações afetivas como o amor, a amizade ou a família. A essa atitude de aceitação emocional estão vinculadas precondições situadas além do controle individual, como a afinidade e a atração, que não podem ser transferidas de acordo com a vontade de outros membros que interagem nesse círculo. É por esse motivo, continua o autor, que esse tipo de relação de reconhecimento possui um particularismo moral que não consegue ser dissolvido em nenhuma tentativa de generalização.

É possível detectar ainda uma segunda forma de desrespeito, assinala Honneth (2007, p.86), que é a negação de direitos e a exclusão social, situação em que seres humanos padecem em sua dignidade por terem sido privados de seus direitos morais e de suas responsabilidades enquanto pessoa legal plena em sua própria comunidade de pertença. Portanto, nesse caso, o combate ao desrespeito tem de mirar sua relação correspondente, isto é, o reconhecimento recíproco por meio do qual os indivíduos passam a se considerar como portadores iguais de direitos, a partir da perspectiva - e isto é relevante - de seus companheiros. Quando os sujeitos sociais adquirem esse reconhecimento legal, a atitude positiva de que passam a desfrutar é a do autorrespeito elementar, na medida em que passam a compartilhar com seus iguais os atributos de um ator moralmente competente. As relações 
juridicamente fundamentadas tornam possível, segundo Honneth (2007, p. 86-87), a generalização das demandas de reconhecimento de direitos na direção tanto de sua extensão material quanto social. Nesse sentido, na ordem legal, a relação de reconhecimento apresenta uma "dinâmica universalizadora" que pode alcançar o poder por meio de lutas históricas dos movimentos sociais.

$\mathrm{O}$ terceiro tipo de desrespeito distinguido por Honneth se refere à depreciação do valor social das formas de autorrealização. Essa desvalorização de feitos ou formas específicas de vida tem como resultado não permitir que os sujeitos em questão criem laços com as habilidades adquiridas ao longo de suas vidas, no que respeita à estima social. À depreciação de valores sociais corresponde um relacionamento positivo de reconhecimento, em que se permite aos indivíduos adquirir uma medida de autoestima que pode ser encontrada na aceitação solidária dos pares e no aspecto social das habilidades de um indivíduo bem como em seu estilo de vida.

As normas éticas que permitem aos indivíduos reconhecer reciprocamente sua individualidade abrem-se assim ao processo de destradicionalização (dado que é por meio da tradição que se propaga o caráter hierárquico e prescritivo do sistema moral de valores), à medida que elas se tornam cada vez mais generalizadas. Por essa razão, continua o filósofo social, o relacionamento de reconhecimento associado à solidariedade incorpora o princípio da diferença igualitária, resultante da pressão proveniente dos sujeitos individualizados, o qual pode agora se desenvolver plenamente.

Partindo desses três padrões de reconhecimento - amor, ordem legal e solidariedade -, Honneth pretende fornecer as bases explicativas para a compreensão da efetivação da integração dentro da qual os seres humanos podem ter certeza de sua "dignidade" e integridade. Sempre que participam de um mundo social no qual encontram os três padrões de reconhecimento, eles podem, então, relacionar-se entre si por meio das formas positivas da autoconfiança, autorrespeito e autoestima. Entretanto, essa linha de argumentação acarreta algumas implicações normativas que exigiriam ampliar o conceito de moralidade social, já que a intenção normativa do reconhecimento distorcido não pode ser abarcada plenamente pelo conceito de "justiça" sem que este seja reconstruído a partir da estrutura de uma concepção formal de boa vida.

Aqui cabe uma observação: o modelo de Honneth, que parte de um conceito de eticidade sobre o qual se ergue uma teoria formal da vida boa e "bem-sucedida", evitaria, de um lado, por meio de uma definição formal do bem, a prescrição normativa de certos valores de uma tradição e comunidade particulares; entretanto, de outro lado, alia-se à crítica ao suposto caráter 
unilateral e incompleto das concepções deontológicas de justiça na tradição kantiana. ${ }^{3}$ Como alerta Rainer Forst (2010, p.331), a teoria precisa extrair seus conceitos e padrões normativos a partir de dentro, isto é, das expectativas (especialmente negativas) dos indivíduos concretos. Só assim poder-se-ia desenvolver um receptor para as condições sociais a partir das quais os sujeitos humanos podem chegar a uma atitude positiva diante de si mesmos.

Mais uma vez, uma linha negativa de argumentação pode fornecer uma forma inicial de raciocínio. Ou seja, sem a suposição de uma certa medida de autoconfiança, de autonomia legalmente considerada e de uma crença na habilidade de alguém é pouco provável imaginar um processo bem-sucedido de autorrealização, que signifique a busca espontânea dos objetivos escolhidos livremente na vida. Com "espontânea" e "livre" Honneth pretende assinalar que, nesse contexto, tais noções significam não apenas a mera ausência de pressão ou influência externa, mas devem implicar ainda a ausência de obstáculos internos, inibições psicológicas e ansiedade.

Considerada positivamente, essa noção de liberdade passa a ser entendida como um tipo de confiança interna, que confere aos indivíduos a segurança exigida para articular suas necessidades e para colocar seus talentos em bom uso. Como já mencionado, tanto essa autoconfiança quanto as formas sem ansiedade de se relacionar com o self configuram aspectos de uma relação positiva com o eu, que só pode ser alcançada por meio da experiência do reconhecimento. Desse modo, o escopo por autorrealização é dependente de precondições não disponíveis aos próprios sujeitos, já que elas só podem ser adquiridas com a cooperação do outro. "Estes diferentes padrões de reconhecimento representam pré-requisitos intersubjetivos, que temos que acrescentar a nossas mentes quando tentamos descrever as estruturas gerais de uma vida bem-sucedida" (Honneth, 2007, p. 88).

Várias restrições foram formuladas para combater essa concepção epistemológica da ordem moral da sociedade apresentada por Honneth. A mais conhecida delas é certamente aquela formulada por Nancy Fraser e publicada em forma de debate entre os dois teóricos, a qual contudo não será discutida aqui. Diferentemente do caminho mais usual, que consiste em debater o par Honneth-Fraser, apresentaremos a seguir um terceiro modo de propor a ideia

\footnotetext{
${ }^{3}$ Honneth (2003, p. 271) distingue a sua posição daquela da tradição kantiana nos seguintes termos: "Nossa abordagem desvia-se da tradição que remonta Kant porque se trata para ela não somente da autonomia moral do ser humano, mas também das condições de autorrealização como um todo; por isso, a moral, entendida como ponto de vista do respeito universal, torna-se um dos vários dispositivos de proteção que servem ao fim universal da possibilidade de uma vida boa".
} 
de reconhecimento a partir de uma certa interpretação da filosofia hegeliana, a saber, aquela formulada por Judith Butler.

\section{Reconhecimento como luta contra as normas em Judith Butler}

Os trabalhos de Judith Butler não costumam figurar no rol de teorias que oferecem uma formulação alternativa ao conceito de reconhecimento. Como se pode ler em uma entrevista concedida a Rasmus Willig (2012), é curioso notar a maneira como Butler enfatiza que a delimitação do reconhecimento como tema central é tanto anterior aos trabalhos de Taylor, Honneth e Fraser como também conformaria parte importante de diferentes debates, usualmente esquecidos por aquelas tentativas de construir uma grande narrativa sobre o que se define hoje como as principais perspectivas sobre o tema. ${ }^{4}$ Butler atribui a G. Spivak uma importante influência no modo como interpreta o surgimento do reconhecimento, abordado por ela no plano sociológico, como um vocabulário importante nas lutas políticas.

Willig (2012, p. 140) argumenta que Butler defende que o reconhecimento adquire maior relevância para aqueles que forem excluídos das estruturas e dos vocabulários da representação política. Isso se tornaria especialmente certeiro para sujeitos que só podem adentrar as estruturas políticas de representação assumindo uma posição que apaga sua agência, cultura e história. Esse, inclusive, seria segundo ela um dos pontos relevantes, que acentuam os marcos de certa tradição hegeliana, apontados por Spivak ao mobilizar os termos dos estudos subalternos. Para quem está fora dessas estruturas e não pode acessar o vocabulário da representação, prossegue Butler interpretando Spivak, o único acesso à representação é episódico, como ocorre, por exemplo, com certos atores sociais em geral invisibilizados que, quando figuram no noticiário, são expostos pela mídia como criminosos/as. O reconhecimento nesses termos é um problema para aqueles seres humanos que não se encaixam nos enquadramentos definidores de qual sexualidade pode ser exercida e qual/quais não ou de que corpos podem ser reconhecidos como sujeitos e quais são apenas 'vítimas' da 'doença' e/ou de algum destino desafortunado.

\footnotetext{
${ }^{4}$ Ludwig Siep (2009), Michael Theunissen (1982), Jay Bernstein (1984), Jessica Benjamin (1998), Patchen Markel (2003), leitoras e leitores, em geral, da Fenomenologia do Espírito [1807], apresentariam contribuições importantes sobre o tema. Do mesmo modo, ainda que em um sentido negativo, a noção de misrecognition informou trabalhos de autores e autoras conhecidos como lacanianos e pós-lacanianos. Nesta lista, Butler inclui também as obras de Gayatri Chakravorty Spivak (1988) e Paul Gilroy (1993) como perspectivas que fazem uso de fontes hegelianas para pensar modos diaspóricos de reprodução cultural.
} 
Ainda que Butler não se identifique como uma autora engajada nos debates contemporâneos sobre o tema do reconhecimento, o conceito recebeu, desde seus primeiros trabalhos sobre a recepção de Hegel pela tradição francesa, tratamento especial por sua relação com a ideia de desejo, seu objeto central. Em linhas gerais, argumenta-se que Butler pretende justificar a ideia segundo a qual existem esquemas de reconhecimento que determinam quem será identificado como sujeito que merece o reconhecimento. Tais esquemas poderiam ser chamados de "processos diferenciados de reconhecibilidade" [recognizability] e designariam processos permeados por relações de poder e de desigualdade centrais para a articulação de qualquer cena de reconhecimento.

Quando uma vida está fora das cenas de reconhecimento - isto é, é privada do acesso à lei e aos direitos, tornando-se uma vida que não é identificada como tal, na medida em que não se enquadra nas normas que definem que sujeito pode e qual não pode ser reconhecido -, trata-se de uma vida que está em risco. Isso significa que a luta entre vida e morte - para recolocar os termos da dialética hegeliana do senhor e do escravo - permanece e é interna às lutas por reconhecimento.

Dito de outro modo, são parte das lutas por reconhecimento as dinâmicas de sujeição. Os seres humanos precisam do reconhecimento dos outros para que sobrevivam socialmente como selves sociais; normalmente, preferem sujeitarse a uma norma e vincular-se a formas de vida que estão dentro dos limites do normal a enfrentar o caminho do sofrimento que representa, no limite, a morte social. O reconhecimento é então interpretado como uma prática social regulatória que funciona por meio de discursos e práticas normalizadoras e disciplinares. É também através dessas cenas de reconhecimento que identidades particulares são produzidas como viáveis - e outras, como inviáveis. Aquele indivíduo que não cabe exatamente no quadro da norma definidora dos termos do reconhecimento não pode sequer ser identificado como misrecognized: 5 trata-se de alguém reconhecido como inimigo, fora da lei, ilegal, aberração. Butler raciocina aqui a partir de uma condição limite, como é aquela de marginalizados/as de toda sorte, juridicamente inexistentes, pessoas sem documentação, ilegais, foragidos não-documentados, apátridas, com o intuito de jogar luz sobre as fronteiras de nossa construção identitária.

\footnotetext{
${ }_{5}^{5}$ Optamos aqui por não traduzir o vocábulo misrecognition e seus múltiplos usos, em virtude da dificuldade de se encontrar, no vernáculo, um termo que expresse de maneira adequada toda a amplitude de seu significado. Mais frutífero talvez seja circunscrever suas possíveis acepções, de modo a permitir que o/a leitor/a construa sua própria interpretação. Em suas variadas aparições na literatura, misrecognition tem sido utilizado para denotar ideias como: 'reconhecimento negado', 'desreconhecimento', 'carência de reconhecimento', 'reconhecimento torto', 'malreconhecimento' e assim por diante.
} 
As normas de reconhecimento são especialmente importantes para que as formas por meio das quais a vulnerabilidade é reproduzida em nosso mundo sejam compreendidas. Butler (2004, p. 41-43) afirma que a vulnerabilidade, precondição para a nossa humanização, é fundamentalmente dependente das normas de reconhecimento e se relaciona à condição de precariedade. A precariedade da vida e do corpo, para além de uma verdade existencial - cada um de nós poderia se encontrar em um contexto de injúria, privação, doença, debilidade ou até morte -, constitui um risco da sociabilidade ao mesmo tempo em que é a sua maior promessa. Estamos relacionados uns com os outros porque precisamos materialmente; mas também somos fortemente dependentes do tato, da linguagem, isto é, somos dependentes de uma série de relações sem as quais não poderíamos viver. Uma situação que não é nem escolhida nem tampouco necessariamente desejada. Do fato de estarmos estreitamente relacionados, nasce a possibilidade da dominação e da subjugação. Porém, é também dessa condição de interdependência que surge a possibilidade do alívio da dor, de conhecermos a amizade e a justiça (Butler, 2015, p. 95-96).

O nascimento é acompanhado da condição de precariedade, explica a filósofa a partir de um argumento intuitivo: é difícil negar a afirmação de acordo com a qual a vida de uma criança depende de uma rede social de ajuda. Cuidados são demandados - e em certas sociedades, como as democracias liberais, até mesmo exigidos - exatamente porque um/a recém-nascido/a pode morrer. Nesse sentido, é somente nos casos em que a vida é reconhecida enquanto tal que sua perda tem algum valor, isto é, pode vir a ser enlutada. Ao adicionar a ideia de luto, Butler $(2015$, p. 33) pretende sustentar que uma vida só é identificada como vida que importa quando pode ser enlutada. Apreender esta condição de enlutamento é, portanto, o que torna possível a apreensão da vida precária, como se pode aprender por meio dos debates sobre Guantánamo, do assédio policial aos árabes nos Estados ou ainda da suspensão de liberdades civis nos EUA, que atuaram no sentido de determinar quem é qualificado para os direitos humanos e quem deles não desfruta (Butler, 2015, p. 115). A nossa capacidade - marcadamente sociocultural - de discernir e nomear o ser do sujeito, por sua vez, é dependente das normas que facilitam ou possibilitam o seu reconhecimento. De onde não se deriva que as normas têm um sentido determinista: como bem enfatiza Butler (2015, p.17), "[o]s esquemas normativos são interrompidos um pelo outro, emergem e desaparecem dependendo das operações mais amplas de poder e com muita frequência se deparam com versões espectrais daquilo que alegam conhecer". Tais operações de poder estão fortemente relacionadas, por meio de seus esquemas normativos, com aquela divisão entre sujeitos que são reconhecidos e vidas que nunca são/ 
serão reconhecidas como tais. Butler está mobilizando aqui, é evidente, uma interpretação foucaultiana da noção de poder. Com Foucault, Butler partilha, em primeiro lugar, a ideia de que o poder se exerce em rede; e, em segundo lugar, que ele tem um caráter produtivo. Como sustenta o mestre francês,

o poder se exerce em rede e, nessa rede, não só os indivíduos circulam, mas estão sempre em posição de serem submetidos a esse poder e também de exercê-lo. Jamais eles são o alvo inerte ou consentidor do poder, são sempre seus intermediários. Em outras palavras, o poder transita pelos indivíduos, não se aplica a eles [...] O indivíduo é um efeito do poder e é, ao mesmo tempo, na mesma medida em que é um efeito seu, seu intermediário: o poder transita pelo indivíduo que ele constitui (Foucault, 2005, p. 35).

Para além da ideia de poder, norma, enquadramento, luto e sofrimento, o reconhecimento invoca, em Butler (2015, p. 19-29), uma noção particular de sujeito, que define o escopo e o sentido do que significa ser reconhecido. Existiria um tipo ideal - que é também normativo - sobre o que é ser um sujeito, ou uma pessoa, que cria, por sua vez, as condições preexistentes das nossas análises, mas também as possibilidades do reconhecimento, de modo que a inteligibilidade de uma vida depende de seu reconhecimento enquanto tal. Nesse sentido, os esquemas de inteligibilidade tanto produzem e condicionam as normas da condição de ser reconhecido quanto pavimentam o caminho para o reconhecimento. Na versão proposta por Butler (2015, p. 21-22), então, o reconhecimento é, tal qual para Hegel, um ato, uma prática intersubjetiva que precisa necessariamente de ao menos dois sujeitos para existir. Dois termos são importantes nesta definição: (i) apreensão - "um modo de conhecer que ainda não é reconhecido", isto é, que não está socialmente disponível; e (ii) inteligibilidade - "esquema (os esquemas) histórico geral que estabelece os domínios do cognoscível". Ora, se a vida é produzida de acordo com as normas pelas quais é reconhecida, não existe nem vida nem morte que não tenham relação com algum enquadramento; enquadramentos, por sua vez, são parte da cena do reconhecimento e atuam para diferenciar as vidas que podemos apreender e reconhecer daquelas que não podemos. Desse modo, em Butler, a luta por reconhecimento é uma batalha com a norma e, ao mesmo tempo, contra ela e seus enquadramentos.

\section{Das potencialidades do reconhecimento negativo - considerações finais}

Tal como reconstruído até aqui, parece impreciso afirmar que Taylor, Honneth e Butler podem ser lidos como parte de um certo campo de debate 
apenas por serem intérpretes, ainda que de tradições e escolas de leitura distintas, da filosofia hegeliana. O que então eles compartilham? Rahel Jaeggi, procura elucidar justamente o que poderia haver de comum a essas abordagens acerca dos modos de compreender o reconhecimento e as lutas sociais que o demandam; propõe que, para tanto, se considere as noções de reconhecimento positivo e negativo.

Segundo Jaeggi (2013, p. 123), o diagnóstico comum a essas teorias é o de que se for possível de fato compreender o reconhecimento com um ato interrelacional de identificação e afirmação de um ser humano ou de algumas de suas características, "então essas teorias partem fundamentalmente da convicção de que, como Mead o formula, nós somos o que somos através de outros e, por conseguinte, como sujeitos dependemos fundamentalmente (e em sentido que ultrapassa a compreensão instrumental) da sociabilidade e da interação com outros".

Tanto a variante positiva (Taylor, Honneth) quanto a negativa (Butler) compartilham algumas ideias: primeiro, a percepção de uma dependência e relacionalidade fundamentais. Dado que os seres humanos não crescem como cogumelos hobbesianos nas florestas, provoca a autora, aceitam que, em virtude de encontrarem-se os sujeitos em uma trama de relações recíprocas de reconhecimento que é também de dependência recíproca, o selfé sempre relacional. Segundo, se a identidade não é um dado, mas algo que se constitui em processos de reconhecimento, disso se segue que não há um interior, ou seja, um "próprio"/self que possa existir e sobreviver sem a mediação do "externo" - o que confirma, portanto, uma vez mais, o caráter relacional do self. Terceiro, o reconhecimento sempre ocorre, na visão dos três autores/as, em uma relação, que é estabelecida na luta e na disputa por reconhecimento com outros selves relevantes.

Entretanto, se há uma linha que conecta essas visões, há também uma série de características que as diferenciam significativamente. De um lado, tem-se as teorias positivas - quadro composto por um panteão de pensadores, que vão de Fichte até Habermas, Taylor e Honneth -, para as quais "a circunstância de que sejamos dependentes do reconhecimento de outros para poder[mos] constituir-nos em nossa [sic] autorrelação é tratada positivamente" (Jaeggi, 2013, p. 125). Assim, então, o fato do reconhecimento ser interpretado de modo tal que carrega consigo o potencial normativo do reconhecimento recíproco simétrico, isto é, de uma sociabilidade bem-sucedida, quando não de um telos, significa que reconhecimento é reconhecença recíproca que, quando alcançada, gera melhoria da qualidade das relações sociais - reconhecimento nesse modo de ver é uma necessidade funcional. Já a versão negativa - 
ilustrada neste artigo pela posição de Butler - interpreta o mesmo ponto de partida de modo radicalmente distinto: o fato de o reconhecimento depender da interpretação do outro é visto como constitutivamente reificante. Ou melhor, o que está em ação, quando se trata das normas de reconhecimento e da sua relação com os atores sociais - precisamente porque as identidades também são constituídas na relação com os outros -, é uma vinculação do sujeito ao poder reconhecedor do qual, vale ressaltar, ele depende. Essa dependência fundamental da existência e do reconhecimento do outro pode ser entendida como uma forma de alienação primária e inaugural de cada um em relação ao social. O reconhecimento é, portanto, nessa visão, sempre assimétrico (Jaeggi, 2013, p. 126-27).

Para além dos argumentos interpretativos sobre como alocar diferentes teorias em um campo de disputa sobre certa tradição filosófica, gostaríamos de argumentar que a formulação do reconhecimento proposta por Butler oferece um uso social-filosófico que faz avançar a agenda investigativa das humanidades - em especial quando refletimos sobre os diagnósticos que se pode produzir mobilizando categorias próprias desse modo de definir o reconhecimento intersubjetivo -, fornecendo contornos de pesquisas interessantes tanto para um encontro entre os diferentes campos disciplinares das ciências sociais e humanas - incluindo a filosofia - quanto para quem identifica como centrais aqueles movimentos sociais e/ou fluxos humanos atuais cujos sujeitos são socialmente reconhecidos como ilegais, anormais ou indesejáveis, para ficarmos apenas com alguns adjetivos.

Gostaríamos de sustentar que há, no mínimo, dois desenhos de pesquisa interessantes para uma investigação que aceita a premissa básica segundo a qual as normas de reconhecimento, ainda que inescapáveis, são parte de um quadro maior composto por uma moldura, que é conformada por determinadas normas e por um modo de lidar com o sofrimento - esses são, em linhas gerais, os termos propostos por Butler desde seu Vida precária (2004).

Um primeiro desenho poderia incidir nas pesquisas sobre as fronteiras do reconhecimento e a possibilidade de desestabilizá-las. Dito de outro modo, tal abordagem poderia fomentar investigações sobre as possibilidades da transformação social mesmo quando se mobiliza um aparato teórico que privilegia as estruturas do poder, as normas e os seus enquadramentos.

Butler e Spivak (2007) percorreram esse caminho quando analisaram o caso dos/as imigrantes ilegais que tomaram as ruas da Califórnia entoando o hino nacional estadunidense em espanhol. As autoras chamam a atenção para o fato de que esses atores sociais, entendidos como ilegais, estariam exercendo um direito, mesmo em uma condição de privação de direitos. Tal ato daqueles/ 
as migrantes é fundamentalmente um ato performativo de exercício da liberdade, que permite às pessoas sem direitos garantidos ocuparem o espaço da aparência e, com isso, exercerem seus direitos. Temos aqui uma interpretação possível da clássica formulação arendtiana do direito a ter direitos.

Essa formulação exige aceitar/compreender que o processo de reivindicar direitos, quando esses ainda não existem e/ou não se encontram garantidos, denota um processo de tradução para a língua dominante, não para ratificar o seu poder, sugerem Butler e Spivak (2007), mas sim para expor e resistir à violência diária e para encontrar uma linguagem por meio da qual é possível reivindicar direitos quando não os temos. Trata-se fundamentalmente de um processo de desestabilização das normas e dos enquadramentos que em certos contextos de poder definem quem são os sujeitos políticos por excelência e quem não poderá ser assim reconhecido.

É precisamente o que fazem aqueles movimentos de ocupação que se mudam para prédios com o intuito de estabelecer os fundamentos para reivindicar direitos de residência. De outro lado, isso equivale a dizer que drags que questionam as normas de gênero ou imigrantes ilegais que cantam o estadonação só podem exercer um direito a ter direitos e questionar as formas de exclusão e dominação em operação na medida mesma em que não são reconhecidos como membros plenos em sua comunidade política. Como concluem as autoras, é pela ação que amiúde se reivindica o direito de poder agir; e estar ou colocar-se de fora das normas ou na sua fronteira pode funcionar como um lugar privilegiado para o seu questionamento e, em alguma medida, suspensão.

Um outro desenho de pesquisa possível, que também é tributário desse modo de operar com e na teoria política e social, tem como ponto de partida a crítica à ideia de identidade. Em suas obras dedicadas aos problemas de gênero, Butler (2010, p. 17-18) formulou uma crítica bastante dura àquelas versões das teorias feministas fundacionistas, que ainda precisavam recorrer a uma noção essencializada de identidade e a um 'sujeito do feminismo'. Nestes escritos, a filósofa parte da constatação de que a teoria feminista, até ao menos a década de 1990, presumia a existência de uma identidade feminina, compreendida pela categoria mulheres, que não só deflagraria os interesses e objetivos feministas no interior de seu próprio discurso como também constituiria o sujeito mesmo em nome do qual a representação política deveria ser almejada - uma posição que não pode nem deve mais ser sustentada no seio do discurso feminista. Isto porque o próprio sujeito "mulheres" não mais poderia ser compreendido em termos estáveis ou permanentes, como mostravam à época os debates feministas sobre os significados do conceito de gênero (Kritsch e Ventura, 2018, p. 115-118). 
Nessa visão, a noção de gênero, categoria central da teoria feminista, passa a ser definida como norma, sustenta Butler (2004, p. 52-53). Ou seja, segundo ela, gênero é o aparato mediante o qual se obtém, juntamente com formas biológicas, psíquicas e performativas, a produção e a normalização do masculino e do feminino, ao mesmo tempo em que pode constituir o artefato por meio do qual tais termos são desconstruídos e desnaturalizados. Um sentido importante da norma é a regulação que, por sua vez, opera como condição para a construção de inteligibilidade cultural. Desviar-se das normas de reconhecimento do gênero significa tornar-se uma aberração - no sentido médico, legal, psíquico - que pode ser explorada rapidamente para fornecer as justificações da sua própria marca reguladora continuada e, com isso, terminar reforçando a norma.

A fusão imediata do gênero com o masculino-feminino, homem-mulher, macho-fêmea, alerta a filósofa (Butler, 2004), termina por levar a cabo a mesma naturalização que a concepção de gênero busca (ou deveria buscar) combater. Desse modo, um discurso restritivo de gênero, assim como da construção da identidade, que insista no binarismo homem-mulher como a única forma de entender o campo do gênero, leva a cabo uma operação regulatória do poder que naturaliza a instância hegemônica e exclui qualquer possibilidade de construir alternativas (nos planos tanto da teoria quanto da ação política).

A reconceituação da identidade como efeito, isto é, como produzida e/ou gerada a partir da necessidade do reconhecimento intersubjetivo desejado pelos agentes sociais, tal como proposta por Butler, permitiria criar possibilidades de agenciamentos que abririam caminhos para a compreensão de que as restrições tácitas que produzem o "sexo" culturalmente inteligível devem ser entendidas como estruturas políticas generativas, e não como fundações naturalizadas. Tal movimento nos permite perceber que considerar a identidade como efeito de uma construção social particular significa também afirmar que ela não é nem inevitavelmente determinada nem totalmente artificial ou arbitrária a ponto de poder ser manejada ao bel prazer por este ou aquele indivíduo isoladamente (como por vezes querem crer certas matrizes atomistas do pensamento político e social). Entender a identidade como efeito de uma construção coletiva não significa necessariamente a exclusão de possibilidades de ação. Isso porque a construção é o cenário necessário à agência, constituindo os próprios termos em que a ação se articula e se torna culturalmente inteligível.

Assim, como já defendemos em outra parte (Butler, 2004, p. 120), a tarefa de pensar as identidades frente aos pluralismos contemporâneos talvez possa vir a ser enriquecida se vier a beber de e inspirar-se em algumas lições dos feminismos contemporâneos - e, em particular, daquele de matriz butleriana, 
hoje já bastante disseminado tanto no mundo acadêmico quanto em meio à militância -, muitos dos quais advogam que o caminho para a transformação social e política eficazes passa, não por estabelecer um ponto de vista fora das identidades construídas, e sim por situar as estratégias de repetição subversivas facultadas por essas construções, afirmar as possibilidades locais de intervenção pela participação nessas práticas de repetições que constituem a identidade ${ }^{6} \mathrm{e}$, desse modo, fazer uso da possibilidade imanente de contestálas, como bem ilustra, para ela, o caso das drag queens.

Longe de invalidar a existência e a importância de vozes distintas, a construção do horizonte explicativo e normativo proposto por Butler expande as esferas e as possibilidades de reivindicação para muito além dos atores representados pelos termos homens/mulheres, feminino/masculino, cidadão/ estrangeiro, nós/outros. Longe de ser capaz de olhar apenas para as estruturas e modos por meio dos quais as relações de poder são parte da nossa sociabilidade, tal posição abre caminhos para refletirmos sobre possibilidades de mudança que nascem justamente naqueles espaços e entre aqueles agentes que não costumam ser considerados atores centrais dos movimentos sociais tradicionais.

Por fim, se as identidades deixassem de ser fixas, como precondição de um silogismo político (inclusive, aquelas relacionadas ao gênero), e se a política não fosse mais compreendida como um conjunto de práticas derivadas dos supostos interesses de um conjunto de sujeitos prontos, acabados e sem arestas, uma nova configuração política poderia surgir. Nesse sentido, urge pôr em xeque, mais do que tudo, as concepções utilitárias/utilitaristas da sociedade e da cultura - na qual bebem, com enorme frequência, tanto liberais quanto marxistas e democratas - e assumir uma noção fluida, porosa, maleável dos atores sociais, de seus objetivos e formas de organização, que se mantenha aberta à negociação dos próprios termos de nosso estar no mundo - tarefa que obviamente não é fácil e encontra resistências de toda sorte, já que implica habitar um universo mental e material por definição incerto, inseguro e desprovido de certezas e convicções últimas.

\section{Referências}

BENJAMIN, Jessica. Like subjects, love objects: essays on recognition and sexual difference. New Haven: Yale University Press, 1998. https://doi.org/10.1023/b: aseb.0000014613.45488.69

\footnotetext{
${ }^{6}$ Tais posições podem ser encontradas hoje em autores/as de matizes tão variados quantas são as suas filiações teóricas e seus compromissos empíricos. Para mencionarmos apenas alguns, confere, além das obras já mencionadas de Butler (1987), Mohanty (1984), Mouffe (1993), Bhabha (1994), Young (2009), Braidotti (1994), Mignolo (2002 e 2013), Brah (1996), Parekh (2001 e 2008), Lugones (2008) entre outro/as.
} 
BERNSTEIN, Jay. From self-consciousness to community: act and recognition in the Master-Slave. In: PELCZYNSKI, Z. A. The state and civil society: studies in Hegel's Political Philosophy. Cambridge: Cambridge University Press, 1984. p. 14-39.

BHABHA, Homi. The location of culture. London: Routledge, 1994.

BRAH, Avtar. Cartographies of diaspora: contesting identities. London: Routledge, 1996.

BRAIDOTTI, Rosi. Nomadic subjects: embodiment and sexual difference in contemporary feminist theory. New York: Columbia University Press, 1994. https:// doi.org/10.22439/fs.v0i17.4305

BUTLER, Judith. Subjects of desire: Hegelian reflections in twentieth-century France. New York: Columbia University Press, 1987. https://doi.org/10.5040/ 9781472545688.ch-001

BUTLER, Judith. Fundamentos contingentes: o feminismo e a questão do 'pósmodernismo'. Cadernos Pagu, Campinas, v. 11, p. 11-42, 1998.

BUTLER, Judith. Precarious life: the powers of mourning and violence. London: Verso, 2004.

BUTLER, Judith. Problemas de gênero: feminismo e subversão de identidade. Rio de Janeiro: Civilização Brasileira, 2010. https://doi.org/10.30715/rbpe.v19. n1.2017.10819

BUTLER, Judith. Quadros de guerra: quando a vida é passível de luto? Rio de Janeiro: Civilização Brasileira, 2015.

BUTLER, Judith; SPIVAK, Gayatri. Who sings the Nation-State. Calcuta: Seagull Books, 2007. https://doi.org/10.1177/0263276409106356

COOLE, Diana. Is class a difference that makes a difference? Radical Philosophy, v. 77, p. $17-25,1996$.

CRAIG, Edward. Pluralism. Routledge encyclopedia of Philosophy. London: Routledge, 2004. v. 14. https://doi.org/10.4324/9780203086711

FORST, Rainer. Contextos da justiça. São Paulo: Boitempo, 2010.

FOUCAULT, Michel. Em defesa da sociedade. São Paulo: Martins Fontes, 2005.

FRASER. Nancy. Da redistribuição ao reconhecimento? Dilemas da justiça na era pós-socialista. In: SOUZA, Jessé (org.). Democracia hoje. Brasília: Editora UNB, 2001. p. 245-282. https://doi.org/10.11606/issn.2316-9133.v15i14-15p231-239

FRASER, Nancy; HONNETH, Axel. Redistribution or recognition? London: Verso, 2003. 
GILROY, Paul. The black Atlantic, modernity and double consciousness. Cambridge, MA: Harvard University Press, 1993.

HONNETH, Axel. Luta por reconhecimento. São Paulo: Editora 34, 2003.

HONNETH, Axel. Reconhecimento ou redistribuição? A mudança de perspectiva na ordem moral da sociedade. In: SOUZA, Jessé; MATOS, Patrícia (org.). Teoria crítica no século 21. São Paulo: Annablume, 2007. p. 79-93.

JAEGGI, Rahel. Reconhecimento e subjugação: da relação entre teorias positivas e negativas da intersubjetividade. Sociologias, Porto Alegre, v. 33, p. 120-140, 2013. https://doi.org/10.1590/s1517-45222013000200005

KYMLICKA, Will. Multicultural citizenship: a liberal theory of minority rights. Oxford: Oxford University Press, 1996. https://doi.org/10.1093/0198290918.001. 0001

KRITSCH, Raquel; VENTURA, Raissa W. Cuidado, justiça e autonomia: contribuições da teoria política feminista para os debates sobre gênero e democracia. Ivs Fvgit, Valparaíso, v. 21, p. 97-124, 2018.

LUGONES, Maria. Colonialidad y género. Tabula Rasa, Bogotá, v. 9, p. 73-101, 2008. https://doi.org/10.25058/20112742.340

MARKELL, Patchen. Bound by recognition. New Jersey: Princeton University Press, 2003.

MIGNOLO, Walter. Historias locales/diseños globales: colonialidad, conocimientos subalternos y pensamiento fronterizo. Madrid: Akal, 2013.

MIGNOLO, Walter. The geopolitics of knowledge and the colonial difference. The South Atlantic Quarterly, v. 101, n. 1, p.57-95, 2002. https://doi.org/ 10.1215/00382876101-1-57

MOHANTY, Chandra T. Under Western eyes: feminist scholarship and colonial discourses. Boundary 2: a journal of postmodern literature and culture, New York, v. 2, p. 333-358, 1984. https://doi.org/10.2307/302821

MOUFFE, Chantal. Feminismo, ciudadanía y política democrática radical. Revista Debate Feminista, Mexico, v. 7, p. 3-22, 1993.

PAREKH, Bhikhu. A new politics of identity: political principles for an interdependent world. Basingstoke: Palgrave Macmillan, 2008. https://doi.org/ 10.1111/j.14682265.2011.00729_35.x

PAREKH, Bhikhu. Integrating minorities. London: Institute of Contemporary Arts, 2001.

PHILLIPS, Anne. Da desigualdade à diferença: um caso grave de deslocamento? Revista Brasileira de Ciência Política, Brasília, n. 2, p. 223-240, jul./dez. 2009. 
SIEP, Ludwig. Anerkennung in der Phänomenologie des Geistes und in der heutigen praktischen Philosophie. In: SCHMIDT am BUSCH, Hans-Christoph; ZURN, Christoph F. (orgs.) Anerkennung. Berlin: Akad, 2009. p. 107-124. https://doi.org/ 10.3726/978-3-653-02093-9/5

SPIVAK, Gayatri. Can the subaltern speak? In: NELSON, Cary; GROSSBERG, Lawrence (org.). Marxism and the interpretation of culture. Chicago: University of Illinois Press, 1988. p. 271-316. https://doi.org/10.1007/978-3-658-13213-2_84

TAYLOR, Charles. Argumentos filosóficos. São Paulo: Edições Loyola, 2000.

THEUNISSEN, Michael. Selbstverwirklichung und Allgemeinheit. Berlin: De Gruyter, 1982. https://doi.org/10.1515/9783110851069

WERLE, Denilson; MELO, Rurion S. Introdução: teoria crítica, teorias da justiça e a 'reatualização' de Hegel. In: HONNETH, Axel. Sofrimento de indeterminação: uma reatualização da filosofia do direito de Hegel. São Paulo: Esfera Pública, 2007. p. 7-44. https://doi.org/10.11606/issn.2318-9800.v0i11p127-140

WILLIG, Rasmus. Recognition and critique: an interview with Judith Butler. Distinktion: Journal of Social Theory, London, v. 13, p. 139-144, 2012. https://doi.org/ 10.1080/1600910x.2012.648742

YOUNG, Iris M. Categorias desajustadas: uma crítica à teoria dual de sistemas de Nancy Fraser. Revista Brasileira de Ciência Política, Brasília, v. 2, p. 193-214, 2009.

Recebido em: 5 jun. 2018

Aprovado em: 18 fev. 2019

Publicado em: 30 jul. 2019

Autora correspondente:

Raissa W. Ventura

Rua Sousa Reis, 120, ap. 51a

05586-080 São Paulo, SP, Brasil

RAQUEL KRITSCH < kritsch@pq.cnpq.br>

Doutora em Ciência Política pela Universidade de São Paulo (USP, São Paulo, SP, Brasil), docente e pesquisadora junto ao PPG em Sociologia da Universidade Estadual de Londrina, em Londrina, PR, Brasil, e coordenadora do Grupo de Teoria Política da Associação Brasileira de Ciência Política.

Orcid: https://orcid.org/0000-0002-5810-0704

RAISSA W. VENTURA < raissa.wventura@gmail.com>

Doutora em Ciência Política pela Universidade de São Paulo (USP, São Paulo, SP, Brasil). Atua como pesquisadora do Núcleo de Pesquisa em Relações Internacionais (Nupri, USP, São Paulo, SP, Brasil) e do Grupo de Estudos em Teoria Política (Getepol, Londrina, PR, Brasil).

Orcid: https://orcid.org/0000-0001-7348-1851

Declaração de coautoria (excerto): "O artigo foi inteiramente elaborado a quatro mãos. Raquel Kritsch redigiu a versão inicial das três primeiras seções e Raissa W. Ventura, as duas últimas. Essas primeiras redações foram compartilhadas entre ambas, revistas e retrabalhadas." 